\title{
Surviving HIV and dying for a smoke: Implications for tobacco use among people living with HIV
}

\author{
Rachel Culbreth, MPH, ${ }^{1}$ Jane Kelly, MD, ${ }^{2}$ David Maggio, MPH, ${ }^{2}$ Pascale M. Wortley, MD, MPH, ${ }^{2} \mathrm{Cherie}^{\mathrm{Drenzek}}$, DVM, MS ${ }^{3}$ \\ ${ }^{1}$ Georgia State University, ${ }^{2}$ Georgia Department of Public Health HIV/AIDS Epidemiology Section, ${ }^{3}$ Georgia Department of Public Health
}

\begin{abstract}
Background: Since the advent of highly active antiretroviral therapy in the mid-nineties, deaths among persons living with HIV (PLWH) have declined nationally. Now a controllable condition, HIV has become a chronic disease, highlighting the importance of tobacco cessation in lowering morbidity and premature mortality. Current smoking is approximately twice as high among PLWH compared with the general population. PLWH who smoke experience higher rates of cardiovascular disease, AIDS-defining illnesses, and cancer than PLWH who do not smoke. Loss of life-years associated with smoking among PLWH is greater than life-years lost from HIV.
\end{abstract}

Methods: Data on current smoking, derived from the 2009-12 Georgia Medical Monitoring Project (MMP) were analyzed. Smoking rates were calculated by demographic characteristics, and results were compared to those from the 2011 Georgia Behavioral Risk Factor Surveillance System (BRFSS), a population-based telephone survey.

Results: The prevalence of current smoking among PLWH was $36.1 \%$, compared with $21.2 \%$ among the general population in Georgia. Smoking prevalence for PLWH generally varied by demographic characteristics according to the same pattern as for the general population, but prevalence was consistently higher among PLWH.

Conclusions: The prevalence of current smoking among PLWH in Georgia is high. Clinical and public health interventions must address smoking cessation as part of HIV care to prevent disease, improve quality of life, and reduce mortality. HIVinfected smokers have more barriers to quitting (alcohol, depression, drug dependence, and inaccurate risk perception) and a lower quit rate than non-HIV-infected smokers. Efficacy studies of behavioral and pharmacological interventions for smoking cessation specific to PLWH are needed.

Key Words: HIV, chronic disease, tobacco use, premature mortality

\section{INTRODUCTION}

Approximately 1.2 million people within the United States are currently living with human immunodeficiency virus (HIV) infections, and, in Georgia 50,436, people were living with diagnosed HIV as of December 31, 2012 (The Georgia Department of Public Health Fact Sheet: HIV Surveillance, Georgia, 2012). Due to the advancement of antiretroviral therapy, people living with HIV (PLWH) are living longer. As PLWH age, they face the same chronic illnesses as the general population, including cardiovascular disease and chronic obstructive pulmonary disease (Moscou-Jackson, Commodore-Mensah, Farley, \& DiGiacomo, 2014).

Smoking prevalence among PLWH is higher than that of the general population. An estimated $21.2 \%$ of adults in the United States smoke cigarettes (CDC, 2013; Browning, Wewers, Ferketich, \& Diaz, 2013), but a study of a nationally representative sample of HIV-infected persons in care found adults with HIV were nearly twice as likely to smoke compared to adults in the general population $(42.4 \%$ and $20.6 \%$, respectively) and were less likely to quit compared to the general population (quit ratios: $32.4 \%$ vs. $51.7 \%$, respectively) (Mdodo et al., 2015). Tobacco use is high among PLWH due to several underlying factors. Both tobacco use and HIV are associated with lower educational achievement, lower income level, concurrent drug use, and mental illness (O’Cleirigh et al., 2015). Tobacco use presents an increased risk of both AIDS-defining and other diseases for HIV-infected smokers, compounding the effect of high rates of smoking in this population (Helleberg et al., 2013).

The purpose of this study was to compare the prevalence of smoking among PLWH in Georgia to that for the general population in Georgia, using data from the Georgia Medical Monitoring Project (MMP), a representative sample of persons in HIV care in Georgia, and data from the Georgia Behavioral Risk Factor Surveillance System (BRFSS). Understanding the prevalence and harmful effects of tobacco use among Georgians living with HIV will inform tobacco cessation programs specific to Georgia as well as educate HIV care providers in Georgia. 


\section{METHODS}

The Georgia MMP data from 2009-2012 were analyzed to estimate smoking prevalence by sociodemographic variables among smokers. MMP is a surveillance system that collects data about behavioral and clinical aspects of PLWH who are currently receiving medical care ("Georgia Medical Monitoring Project (MMP) | Georgia Department of Public Health"). MMP utilizes a three-stage, probability sampling method, and Georgia is one of 26 states and cities across the United States that participates. Within project areas, facilities and patients within those facilities are randomly selected. Interviews are conducted either face-to-face or via telephone to obtain behavioral information, and medical records are used to obtain clinical information. To be eligible to participate, individuals are required to be HIVinfected, 18 years of age or older at the time of the interview, and actively receiving medical care for HIV. Data from the Georgia MMP are weighted to produce a representative sample of all adult Georgians receiving medical care for HIV (McNaghten et al., 2007; Blair et al., 2011; Frankel et al., 2012). Because results varied minimally during 2009-2012, data from the four survey years were pooled to achieve a larger sample size.

The Georgia Behavioral Risk Factor Surveillance System (BRFSS) data from 2011 were analyzed to estimate smoking prevalence among the general population of Georgia adults by sociodemographic variables. BRFSS collects information regarding health risk behaviors, health conditions, and use of healthcare services. Data are collected in all 50 states, and the surveys are completed via telephone interviews. Beginning in 2011, BRFSS collected data from both landline telephones, using a disproportionate stratified sampling method, and cellular telephones, using a random, probability sampling method. BRFSS data, like MMP data, are weighted to produce nationally representative samples as well as representative samples for each state ("CDC - BRFSS,"). Analyses were conducted using SAS 9.2.

\section{RESULTS}

Smoking prevalence among PLWH in Georgia was almost twice as high as smoking prevalence among the general population (36.1\% vs. 21.2\%). For PLWH, current smoking was more common among females than males, whites than blacks, persons with a high school education or less, and persons 25 years and older. With the exception of differences by sex, similar patterns were seen in the general population. Within each subgroup, current smoking was higher among PLWH (Table 1).

\begin{tabular}{|c|c|c|c|c|}
\hline & \multicolumn{2}{|c|}{ PLWH } & \multicolumn{2}{|c|}{ All Adults } \\
\hline & \multicolumn{2}{|c|}{ Georgia MMP 2009-2012 } & \multicolumn{2}{|c|}{ Georgia BRFSS 2011} \\
\hline & Unweighted $N^{*}$ & $\begin{array}{l}\text { Smoker \% } \\
\text { (Weighted) }\end{array}$ & Unweighted N & $\begin{array}{l}\text { Smoker \% } \\
\text { (Weighted) }\end{array}$ \\
\hline Overall & 607 & 36 & 1,612 & 21 \\
\hline \multicolumn{5}{|l|}{ Sex } \\
\hline Female & 172 & 39 & 942 & 18 \\
\hline Male & 429 & 35 & 670 & 23 \\
\hline \multicolumn{5}{|l|}{ Race/Ethnicity } \\
\hline White & 138 & 41 & 1,159 & 24 \\
\hline Black & 407 & 34 & 331 & 17 \\
\hline Hispanic & 26 & $-*$ & 46 & 13 \\
\hline \multicolumn{5}{|l|}{ Education } \\
\hline$<$ High school & 95 & 55 & 292 & 36 \\
\hline H.S. graduate & 172 & 43 & 562 & 24 \\
\hline$>$ High school & 340 & 27 & 752 & 15 \\
\hline \multicolumn{5}{|l|}{ Age in years } \\
\hline $18-24$ & 29 & $-*$ & 84 & 25 \\
\hline $25-44$ & 261 & 40 & 425 & 24 \\
\hline $45-64$ & 290 & 36 & 780 & 22 \\
\hline $65+$ & 26 & $-*$ & 288 & 13 \\
\hline \multicolumn{5}{|l|}{ Income } \\
\hline Less than $\$ 20 \mathrm{~K}$ & 137 & 40 & 492 & 33 \\
\hline$\$ 20 \mathrm{~K}$ or more & 103 & 24 & 919 & 17 \\
\hline
\end{tabular}

*unreliable estimate 


\section{DISCUSSION}

In the United States, tobacco use is the leading cause of preventable illness and death, and after viral suppression, tobacco cessation remains the number one health priority for PLWH who smoke. In Georgia, rates of current smoking are almost twice as high among PLWH than among the general population. The findings are consistent with those of other studies on smoking prevalence among PLWH.

PLWH who smoke have a substantially increased risk of cardiovascular disease; AIDS-defining conditions, including candidiasis, bacterial pneumonia, cervical cancer, and anal cancer; lung cancer; and liver cancer (Helleberg et al., 2013; Kwong \& Bouchard-Miller, 2010; Lifson 2010). Smoking causes a systemic inflammation and decreases immune function, which contributes to the increased risk of diseases and certain types of cancers (Helleberg et al., 2013) . Compared to smokers in the general population, HIVinfected smokers are more susceptible to developing chronic obstructive pulmonary disorder (Crothers et al., 2006). Premature mortality is also substantially increased in PLWH who smoke compared to those who do not smoke (Figure 1) (Helleberg et al., 2013). Life expectancy for a 35-year-old HIV patient who smokes is 62.6 years, compared with 78.4 years for a non-smoking patient with HIV. Both all-cause and AIDS mortality are higher among PLWH who smoke, including a nearly five-fold increased risk of death caused by cardiovascular disease and cancer compared to HIVinfected non-smokers (Helleberg et al, 2013). The attributable risk of death associated with smoking is $61.5 \%$ among PLWH compared to $34.2 \%$ among HIV-negative controls.

Cigarette smoking is associated with lower adherence to antiretroviral therapy (ART) (Shuter \& Bernstein, 2008), and smoking is also associated with a greater risk of virologic failure (Feldman et al., 2006). Even after controlling for adherence, cigarette smoking was associated with a decrease in the efficacy of ART, suggesting that an underlying biological mechanism exists between smoking and ART (O'Cleirigh et al., 2015).

Due to the high prevalence of smoking among PLWH and the increased risk of disease and premature mortality among HIV-infected smokers, tobacco cessation should be a goal for HIV care providers. However, there are many barriers to quitting. Inaccurate risk perceptions, depression and mental illness, and concurrent alcohol and drug use all negatively impact tobacco cessation efforts (O'Cleirigh et al., 2015). Cessation counseling programs for patients who are codependent on other substances (e.g., alcohol and marijuana) are more successful when both substance abuse cessation and tobacco cessation are included than when either cessation program is implemented alone (Helleberg et al., 2013).

Recent molecular biology research demonstrates that nicotine causes structural changes in $\Delta$ FosB receptors in the mouse brain striatum, which is a factor in the development PLWH (Moscou-Jackson et al., 2014). Also, interventions that addressed co-occurring substance abuse and psychiatric of addiction behavior (Rosenberg, 2014; Kandel \& Kandel, 2014). Priming mice with nicotine also enhances the effect of cocaine. This priming effect has implications for harm reduction approaches, such as the use of e-cigarettes (Levine et al., 2005). Since e-cigarettes are nicotine-delivery devices, they do not provide an optimal strategy for harm reduction for populations with high substance abuse prevalence due to the effect of nicotine on enhancement of the effects of other drugs. By such enhancement, ecigarettes pose the same risks as traditional cigarettes and present additional barriers to cessation of tobacco and substance use (Kandel \& Kandel, 2014).

In the general population, only $20.9 \%$ of smokers receive tobacco cessation counseling, and only $7.6 \%$ receive tobacco cessation medication (Jamal et al., 2012). Some studies have demonstrated that providers of healthcare to PLWH are more likely to discuss tobacco cessation strategies with their patients than primary care providers; however, only half of all such providers report screening and counseling for tobacco use (Benard et al., 2007; Tesoriero, Gieryic, Carrascal, \& Lavigne, 2010). Shuter et al. examined smoking behaviors among PLWH and found and $83 \%$ of participants reported their primary care provider initiated discussions regarding smoking. However, only $32.8 \%$ were referred to a quit line, and only $5.3 \%$ were referred to a smoking cessation program (Shuter, Bernstein, \& Moadel, 2012). Reasons for lack of adequate counseling by those providing care to PLWH were that tobacco cessation counseling involved time limitations and/or that they felt unqualified to counsel (Shuter et al., 2012).

\section{Limitations}

PLWH who are not receiving care or not receiving consistent care were not included in this sample. Individuals receiving care may be more health conscious and less likely to smoke than individuals who are not receiving care; therefore, smoking prevalence among Georgians living with HIV may be underestimated. The response rates for the Georgia MMP were $27.39 \%$ for $2009,17.58 \%$ for 2010 , $23.23 \%$ for 2011 , and $34.71 \%$ for 2012 . The adjusted response rate for Georgia BRFSS was $49.92 \%$ for 2011. Lower response rates could lead to nonresponse bias and affect the generalizability of results.

\section{Implications for Public Health}

Findings of high smoking prevalence among PLWH combined with the increased risk of diseases and mortality for PLWH smokers highlight the importance of tobacco cessation among this population. These results should inform tobacco cessation programs tailored to people living with HIV in Georgia. A recent review assessed tobacco cessation programs among HIV-positive persons (MoscouJackson et al., 2014). Interventions that incorporated cell phone cessation strategies were the most successful at increasing smoking cessation rates (Vidrine, Arduino, Lazev, \& Gritz, 2006; Vidrine, Marks, Arduino, \& Gritz, 2012). The review concluded that the most successful interventions were adjusted to address specific needs of disorders were more successful at achieving tobacco cessation than interventions that did not address these 
comorbidities (Moscou-Jackson et al., 2014). Combinations of different cessation strategies, including pharmacotherapy, education, and counseling, would be more beneficial to this population (Moscou-Jackson et al., 2014).

\section{References}

Benard, A., Bonnet, F., Tessier, J.-F., Fossoux, H., Dupon, M., Mercie, P., ... Groupe d'Epidemiologie Clinique du SIDA en Aquitaine (GECSA). (2007). Tobacco addiction and HIV infection: toward the implementation of cessation programs. ANRS CO3 Aquitaine Cohort. AIDS Patient Care and STDs, 21(7), 458-468. http://doi.org/10.1089/apc.2006.0142

Blair, J. M., McNaghten, A. D., Frazier, E. L., Skarbinski, J., Huang, P., \& Heffelfinger, J. D. (2011). Clinical and behavioral characteristics of adults receiving medical care for HIV infection --- Medical Monitoring Project, United States, 2007. Morbidity and Mortality Weekly Report. Surveillance Summaries (Washington, D.C.: 2002), 60(11), 1-20.

Browning, K. K., Wewers, M. E., Ferketich, A. K., \& Diaz, P. (2013). Tobacco use and cessation in HIV-infected individuals. Clinics in Chest Medicine, 34(2), 181-190. http://doi.org/10.1016/j.ccm.2013.01.005

CDC - BRFSS. (n.d.). Retrieved May 18, 2015, from http://www.cdc.gov/brfss/

Centers for Disease Control and Prevention (CDC). (2013). Vital signs: current cigarette smoking among adults aged $\geq 18$ years with mental illness - United States, 2009-2011. MMWR. Morbidity and Mortality Weekly Report, 62(5), 81-87.

Feldman, J. G., Minkoff, H., Schneider, M. F., Gange, S. J., Cohen, M., Watts, D. H., ... Anastos, K. (2006). Association of cigarette smoking with HIV prognosis among women in the HAART era: a report from the women's interagency HIV study. American Journal of Public Health, 96(6), 1060-1065. http://doi.org/10.2105/AJPH.2005.062745

Frankel, M. R., McNaghten, A., Shapiro, M. F., Sullivan, P. S., Berry, S. H., Johnson, C. H., ... Bozzette, S. A. (2012). A probability sample for monitoring the HIV-infected population in care in the U.S. and in selected states. The Open AIDS Journal, 6, 67-76. http://doi.org/10.2174/1874613601206010067

Georgia Medical Monitoring Project (MMP) | Georgia Department of Public Health. (n.d.). Retrieved February 16, 2015, from http://dph.georgia.gov/georgia-medical-monitoring-project-mmp

Helleberg, M., Afzal, S., Kronborg, G., Larsen, C. S., Pedersen, G., Pedersen, C., ... Obel, N. (2013). Mortality attributable to smoking among HIV-1-infected individuals: a nationwide, population-based cohort study. Clinical Infectious Diseases: An Official Publication of the Infectious Diseases Society of America, 56(5), 727-734. http://doi.org/10.1093/cid/cis933

Jamal, A., Dube, S. R., Malarcher, A. M., Shaw, L., Engstrom, M. C., \& Centers for Disease Control and Prevention (CDC). (2012). Tobacco use screening and counseling during physician office visits among adults--National Ambulatory Medical Care Survey and National Health Interview Survey, United States, 2005-2009. MMWR. Morbidity and Mortality Weekly Report, 61 Suppl, 38-45.

Kandel, E. R., \& Kandel, D. B. (2014). Shattuck Lecture. A molecular basis for nicotine as a gateway drug. The New England Journal of Medicine, 371(10), 932-943. http://doi.org/10.1056/NEJMsa1405092

Kwong, J., \& Bouchard-Miller, K. (2010). Smoking cessation for persons living with HIV: a review of currently available interventions. The Journal of the Association of Nurses in AIDS
Care: JANAC, http://doi.org/10.1016/j.jana.2009.03.007

Levine, A. A., Guan, Z., Barco, A., Xu, S., Kandel, E. R., \& Schwartz, J. H. (2005). CREB-binding protein controls response to cocaine by acetylating histones at the fosB promoter in the mouse striatum. Proceedings of the National Academy of Sciences of the United States of America, 102(52), 1918619191. http://doi.org/10.1073/pnas.0509735102

McNaghten, A. D., Wolfe, M. I., Onorato, I., Nakashima, A. K., Valdiserri, R. O., Mokotoff, E., ... Sullivan, P. S. (2007). Improving the representativeness of behavioral and clinical surveillance for persons with HIV in the United States: the rationale for developing a population-based approach. PloS One, 2(6), e550. http://doi.org/10.1371/journal.pone.0000550

Mdodo, R., Frazier, E. L., Dube, S. R., Mattson, C. L., Sutton, M. Y., Brooks, J. T., \& Skarbinski, J. (2015). Cigarette Smoking Prevalence Among Adults With HIV Compared With the General Adult Population in the United StatesCross-sectional SurveysCigarette Smoking Prevalence Among Adults With HIV. Annals of Internal Medicine, 162(5), 335-344. http://doi.org/10.7326/M14-0954

Moscou-Jackson, G., Commodore-Mensah, Y., Farley, J., \& DiGiacomo, M. (2014). Smoking-Cessation Interventions in People Living With HIV Infection: A Systematic Review. Journal of the Association of Nurses in AIDS Care, 25(1), 3245. http://doi.org/10.1016/j.jana.2013.04.005

O'Cleirigh, C., Valentine, S. E., Pinkston, M., Herman, D., Bedoya, C. A., Gordon, J. R., \& Safren, S. A. (2015). The unique challenges facing HIV-positive patients who smoke cigarettes: HIV viremia, ART adherence, engagement in HIV care, and concurrent substance use. AIDS and Behavior, 19(1), 178-185. http://doi.org/10.1007/s10461-014-0762-7

Rosenberg, J. M. (2014). A molecular basis for nicotine as a gateway drug. The New England Journal of Medicine, 371(21), 2038. http://doi.org/10.1056/NEJMc1411785\#SA1

Shuter, J., \& Bernstein, S. L. (2008). Cigarette smoking is an independent predictor of nonadherence in HIV-infected individuals receiving highly active antiretroviral therapy. Nicotine \& Tobacco Research: Official Journal of the Society for Research on Nicotine and Tobacco, 10(4), 731-736. http://doi.org/10.1080/14622200801908190

Shuter, J., Bernstein, S. L., \& Moadel, A. B. (2012). Cigarette smoking behaviors and beliefs in persons living with HIV/AIDS. American Journal of Health Behavior, 36(1), 75-85.

Tesoriero, J. M., Gieryic, S. M., Carrascal, A., \& Lavigne, H. E. (2010). Smoking among HIV positive New Yorkers: prevalence, frequency, and opportunities for cessation. AIDS and Behavior, 14(4), 824-835. http://doi.org/10.1007/s10461-008-9449-2

The Georgia Department of Public Health Fact Sheet: HIV Surveillance, Georgia, 2012. (n.d.). Retrieved from https://dph.georgia.gov/sites/dph.georgia.gov/files/HIV_EPI_Fa ct_Sheet_Surveillance_2012.pdf

Vidrine, D. J., Arduino, R. C., Lazev, A. B., \& Gritz, E. R. (2006). A randomized trial of a proactive cellular telephone intervention for smokers living with HIV/AIDS. AIDS (London, England), 20(2), 253-260 http://doi.org/10.1097/01.aids.0000198094.23691.58

Vidrine, D. J., Marks, R. M., Arduino, R. C., \& Gritz, E. R. (2012). Efficacy of cell phone-delivered smoking cessation counseling for persons living with HIV/AIDS: 3-month outcomes. Nicotine \& Tobacco Research: Official Journal of the Society for Research on Nicotine and Tobacco, 14(1), 106-110. http://doi.org/10.1093/ntr/ntr121 